\title{
Relationship between ambient ultraviolet radiation and Hodgkin lymphoma subtypes in the United States
}

\author{
Emily M Bowen ${ }^{1}$, Ruth M Pfeiffer ${ }^{1}$, Martha S Linet ${ }^{1}$, Wayne T Liu ${ }^{1}$, Dennis D Weisenburger ${ }^{2}$, \\ D Michal Freedman ${ }^{1}$ and Elizabeth K Cahoon*,1 \\ ${ }^{1}$ Division of Cancer Epidemiology and Genetics, National Cancer Institute, National Institutes of Health, US Department of \\ Health and Human Services, 9609 Medical Center Drive, Rockville, MD 20850, USA and '2Department of Pathology, City of Hope \\ National Medical Center, 1500 East Duarte Road, Duarte, CA 91010, USA
}

Background: There are few modifiable risk factors for Hodgkin lymphoma (HL), the most common cancer among young adults in Western populations. Some studies have found a reduced risk with exposure to ultraviolet radiation (UVR), but findings have been inconsistent and limited to $\mathrm{HL}$ as a group or the most common subtypes.

Methods: We evaluated UVR and incidence of HL subtypes using data from 15 population-based cancer registries in the United States from 2001 to 2010 ( $n=20$ 021). Ground-based ambient UVR estimates were linked to county of diagnosis. Incidence rate ratios (IRRs) and 95\% confidence intervals (Cls) were calculated for UVR quintiles using Poisson regression models adjusted for age, sex, race/ethnicity, diagnosis year, and registry.

Results: Hodgkin lymphoma incidence was lower in the highest UVR quintile for nodular sclerosis (IRR $=0.84,95 \% \mathrm{Cl}=0.75-0.96$, $P$-trend $<0.01)$, mixed cellularity/lymphocyte-depleted $(\mathrm{IRR}=0.66,95 \% \mathrm{Cl}=0.51-0.86, P$-trend $=0.11)$, lymphocyte-rich $(\mathrm{IRR}=0.71$, $95 \% \mathrm{Cl}=0.57-0.88, P$-trend $<0.01)$, and nodular lymphocyte predominant $\mathrm{HL}(\mathrm{IRR}=0.74,95 \% \mathrm{Cl}=0.56-0.97, P$-trend $<0.01)$, but 'not otherwise specified' HL (IRR $=1.19,95 \% \mathrm{Cl}=0.96-1.47$, $P$-trend $=0.11)$.

Conclusions: This is the largest study of UVR and HL subtypes covering a wide range of UVR levels; however, we lack information on personal UVR and other individual risk factors. These findings support an inverse association between UVR and HL.

Hodgkin lymphoma (HL) is the most common cancer in young adults (15-19 years) in the United States. A total of 9190 new cases and 1180 deaths were estimated to occur in the United States in 2014 (Howlader et al, 1975-2011). The most consistently identified risk factors are a family history of HL, age (high-risk groups include 15-30 years and over 55 years), male sex, delayed infection with Epstein-Barr virus (EBV), and diseases or treatments resulting in severe immunodeficiency (e.g., human HIV infection and immunosuppressing treatment after organ transplantation; Jarrett, 2002; Yug and Linch, 2003; Cartwright and Watkins, 2004; Hjalgrim et al, 2007). Although EBV contributes substantially to the aetiology of classical HL (CHL; Jarrett, 2002), especially the mixed cellularity/lymphocyte-depleted subtype (Jarrett et al, 1996; Glaser et al, 1997), the aetiology for much of HL remains unclear.

Solar ultraviolet radiation (UVR) exposure measured in different ways has been related to a reduced risk of HL in some epidemiological studies (Boscoe and Schymura, 2006; Monnereau et al, 2013; van Leeuwen et al, 2013), whereas others have found no association (Smedby et al, 2005; Petridou et al, 2007; Boffetta et al, 2008; Grandin et al, 2008; Chang et al, 2011; Wong et al, 2012). Studies using self-reported personal UVR measures (e.g., time spent outdoors and sunburn history) have been too small to evaluate the rare HL subtypes (Smedby et al, 2005; Petridou et al, 2007; Boffetta et al, 2008; Grandin et al, 2008; Wong et al, 2012)

*Correspondence: Dr EK Cahoon; E-mail: cahoonek@mail.nih.gov

Received 1 June 2015; revised 18 September 2015; accepted 13 October 2015; published online 18 February 2016

(c) 2016 Cancer Research UK. All rights reserved 0007-0920/16 
and have usually been set in locations with limited ambient UVR variability (Smedby et al, 2005; Petridou et al, 2007; Grandin et al, 2008; Wong et al, 2012). A pooled analysis with a wide range of ambient UVR found an inverse relationship between several measures of personal UVR exposure and EBV-positive HL, but was not able to evaluate the UVR relationship for the rare HL subtypes (lymphocyte-rich CHL and nodular lymphocyte predominant HL; Monnereau et al, 2013). Only one study, from Australia has examined the relationship between UVR and all subtypes of HL, but used latitude as a surrogate for ambient UVR exposure (van Leeuwen et al, 2013). Hodgkin lymphoma is increasingly recognised as a heterogeneous group of lymphoid neoplasms with differing etiologies, so investigation by subtype and demographic risk factors is warranted (Morton et al, 2007; Mani and Jaffe, 2009).

We evaluated the relationships between solar ambient UVR and the subtype-specific incidence of HL using data from the Surveillance, Epidemiology, and End Results (SEER) Program from 2001 to 2010 linked to United States county-level, ground-based ambient UVR (Tatalovich et al, 2006). This is the largest study exploring the association between ambient UVR and HL, containing over eight times more cases than the second largest study (van Leeuwen et al, 2013) and uses a refined measure of ambient UVR that has been recently developed for epidemiological study (Tatalovich et al, 2006).

\section{MATERIALS AND METHODS}

Study population and data organisation. The study population is derived from 15 non-overlapping, population-based cancer registries in the SEER 18 database, which contains the widest geographic range and comprises $\sim 26 \%$ of the US population. The registries include San Francisco, Los Angeles, San JoseMonterey, greater California, Seattle-Puget Sound, Utah, New Mexico, Detroit, Iowa, Kentucky, Louisiana (except for cases diagnosed from July-December 2005 which were excluded due to Hurricanes Katrina and Rita), Connecticut, New Jersey, Atlanta, rural Georgia, and greater Georgia (Figure 1; Surveillance, Epidemiology, and End Results (SEER) Program, 2013). Hawaii, Alaska, and Arizona Indian registries were excluded because they were outliers for ambient UVR and/or did not collect information on all races/ethnicities (the Alaska registry contains Native Alaskans, the Arizona registry consists of Native Americans, and Hawaii contains a very small number of cases hat fall into the major racial ethnic groups of non-Hispanic White, Hispanic White, and Black). Surveillance, Epidemiology, and End Results registries collect information on patient demographics, tumour characteristics (site and morphology), and year and county of diagnosis. This study included only cases who were diagnosed with a first primary HL before age 85 years and between 2001 and 2010 inclusive. Because of small sample sizes, races/ethnicities other than non-Hispanic White, Hispanic White, and Black were excluded. To protect patient confidentiality, SEER does not have personal identifiers and this study was exempt from IRB review.

As HIV is a strong risk factor for HL, and HIV cases cluster in certain geographical locations, confounding by HIV infection has the potential to substantially bias relative risk estimates(Carbone et al, 2009). Therefore, we excluded HL cases that were flagged by SEER as HIV positive. However, HIV status is not reported by the Iowa registry due to privacy concerns stemming from a small number of HIV-positive cases. As sensitivity analyses excluding the Iowa registry did not significantly impact our results, all HL cases from Iowa are included in these analyses. In support of the comprehensiveness of this flag, it has been reported that among HL cases in SEER (200-2010) who died and did not have a positive HIV flag (no HIV or unknown), HIV was found on only $0.2 \%$ of death certificates (Shiels et al, 2014).
For each county, counts of HL were stratified by year of diagnosis group (2001-2005 and 2006-2010), sex, age group (0-14, $15-24,25-44,45-64$ and 65-84 years), race (non-Hispanic White, Hispanic White and Black), SEER registry, and ambient annual UVR quintile. The computation of UVR quintiles is detailed below. Corresponding population counts were obtained from the 2000 US census.

Outcomes. The HL cases consisted of patients diagnosed with $\mathrm{CHL}$ and non-CHL subtypes using the International Classification of Disease for Oncology third edition (ICD-O-3) morphology codes (Morton et al, 2007), which have undergone changes in classification over time (Morton et al, 2007). Classical HL subtypes include nodular sclerosis (ICD-0-3 codes: 9663-67), mixed cellularity/lymphocyte depleted (ICD-0-3 codes: 9652-55), lymphocyte rich (ICD-0-3 code: 9651), and not otherwise specified (ICD-0-3 codes: 9650, 9661-62). Hodgkin lymphoma classification is generally based on differences in the pathological findings of Reed-Sternberg cell morphology and the cellular composition of the microenvironment around these cells. Non-CHL consists of the rare nodular lymphocyte predominant subtype (ICD-0-3 code: 9659) in which Reed-Sternberg cells strongly express B lymphocyte markers such as CD20. Only patients diagnosed after the introduction of the World Health Organization Classification (Jaffe et al, 1999) and translation into ICD-O-3 (Fritz, 2000) were included in these analyses. Hodgkin lymphoma cases were grouped into subtypes as defined by the InterLymph hierarchical classification for epidemiologic research (Turner et al, 2010).

Ambient ultraviolet radiation. Quintiles of ambient UVR were determined by the county of residence at time of HL diagnosis. Ambient UVR was derived using the National Solar Radiation Database, which provided summaries of hourly UVR estimates taken at 239 US radiation stations from 1961 to 1990 (Tatalovich et al, 2006). Average annual daily ambient UVR was modelled to represent the biological action spectrum associated with sunburn. This is most heavily weighted towards the UVB spectrum (280$315 \mathrm{~nm}$ ). Measurements of UVR between weather stations were interpolated based on elevation across the United States to estimate county-level UVR (Tatalovich et al, 2006). Annual estimates of UVR have varied little over time as the start of satellite-based measurements in the late 1970s, aside from relatively small fluctuations due to the 11-year solar cycle (Lean et al, 1997; Newman et al, 2008). Surveillance, Epidemiology, and End Results counties were ranked by UVR and assigned to quintiles 1 (lowest UVR) through 5 (highest UVR) (Figure 1), so that members of a county would all be assigned the same UVR quintile. The ranges of the ambient UVR quintiles were 3235-3998, 3999-4204, 4205-4562, 4563-4603, and 4604-5439 $\mathrm{Wh} \mathrm{m}^{-2}$.

Statistical analysis. We examined the relationship between UVR and total HL and HL subtypes by calculating incidence rate ratios (IRRs) for UVR quintiles (coded as 1-5) and 95\% confidence intervals (CIs) using Poisson regression models adjusted for sex, age group, year of diagnosis group, race, and registry. Systematic geographical differences in ascertainment or diagnosis could affect results, thus the SEER registry was included as a random effect in all models. All models contained the natural log of the population size as an offset. In sensitivity analyses, use of zero-inflated Poisson regression models did not change results. Trends were evaluated by examining the linear relationships between continuous UVR (averaged over each quintile) and the incidence of HL and its subtypes.

To evaluate whether these relationships were modified by diagnosis year, age, sex, or race/ethnicity, we included multiplicative interaction terms in the Poisson models. Interaction $P$-values were based on the Wald test and used continuous UVR (averaged over each quintile). We tested for heterogeneity in the relationships between UVR and HL subtypes using the Cochran's 


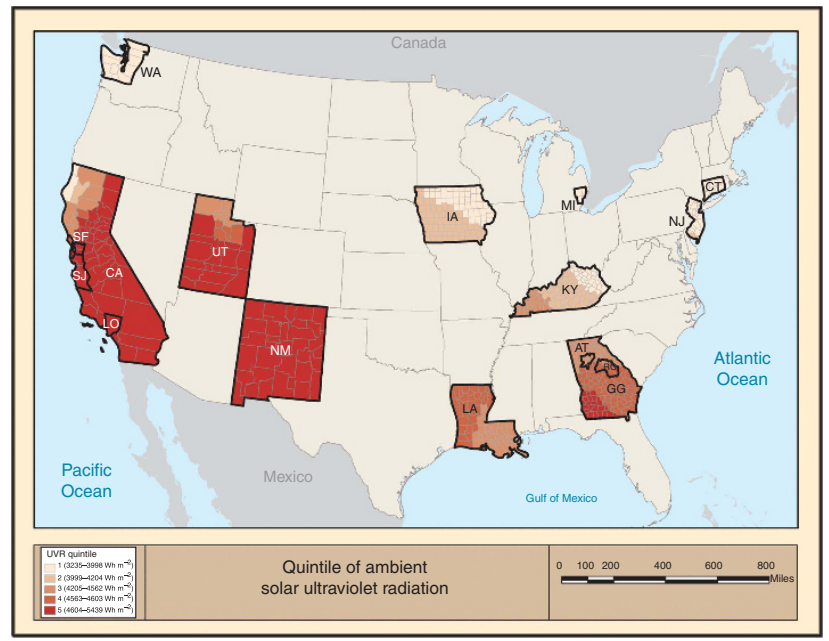

Figure 1. Quintiles of ambient ultraviolet radiation in the United States for 15 population-based cancer registries participating in the Surveillance, Epidemiology, and End Results Program between 2001 and 2010 .

Q statistic for meta-analysis (Cochran, 1954). To describe the potential for misclassification of exposure due to residential movement before residence at diagnosis, we compared UVR from birth state (in tertiles) to UVR at diagnosis among HL cases with information on birth state. Statistical tests were two sided with a specified type-I error of 0.05 . Poisson regression was performed with the GLIMMIX procedure and Laplace method using SAS software V9.3 (SAS Institute, Inc., Cary, NC, USA). The Q statistics for heterogeneity were computed in Stata 11 (StataCorp, 2015).

\section{RESULTS}

A total of 20021 cases of HL were included in the study, of which 19097 (95\%) were CHL and 924 (5\%) were nodular lymphocyte predominant HL (Table 1). Hodgkin lymphoma was more common among men than women for all subtypes except nodular sclerosis CHL, for which we observed an even sex distribution and nodular sclerosis was the most common subtype among adolescents and young adults ( $<45$ years). Over $70 \%$ of all HL cases occurred among non-Hispanic Whites, whereas Hispanic Whites and Blacks comprised $15 \%$ and $11 \%$ of all cases, respectively.

The risk was significantly lower for UVR Q5 vs Q1 for total HL (IRR $=0.88 ; 95 \%$ CI: 0.81-0.95), nodular sclerosis CHL $(\mathrm{IRR}=0.84 ; 95 \%$ CI: $0.75-0.96)$, mixed cellularity/lymphocytedepleted CHL $(I R R=0.66 ; 95 \%$ CI: 0.51-0.86), lymphocyte-rich CHL $($ IRR $=0.71 ; 95 \%$ CI: $0.57-0.88)$, and nodular lymphocyte predominant HL (IRR $=0.74 ; 95 \%$ CI: 0.56-0.97; Table 2). A significant inverse trend of HL risk with increasing UVR was found for total HL $(P$-trend $<0.001)$, nodular sclerosis CHL ( $P$-trend $<0.001)$, lymphocyte-rich CHL $(P$-trend $=0.005)$, and nodular lymphocyte predominant HL $(P$-trend $<0.001$; Table 2 ; Figure 2$)$. For CHL not otherwise specified, we did not observe a significant trend with increasing UVR quintiles $(P$-trend $=0.503)$. We observed significant heterogeneity $(P=0.013)$ across all subtypes with respect to continuous UVR (Figure 2), but no heterogeneity when CHL not otherwise specified was excluded $(P=0.64)$.

There was no evidence of significant statistical interaction on the multiplicative scale for UVR and HL subtypes or total HL by diagnosis year, sex, or race/ethnicity. However, age category $(<45$ vs $\geqslant 45$ years $)$ did significantly modify the association between UVR and risk for total HL $(P$ for interaction $<0.001)$ and the mixed cellularity/lymphocyte-depleted CHL subtype
( $P$ for interaction $=0.009$ ). For those diagnosed with $\mathrm{HL}<45$ years of age, the IRR for UVR Q5 vs Q1 was $0.84(95 \%$ CI: $0.76-0.93, P$-trend $<0.0001)$, whereas for those diagnosed at age $\geqslant 45$ years or older, the IRR for UVR Q5 vs Q1 was 0.91 (95\% CI: $0.82-1.01, P$-trend $=0.32)$. Similarly, for mixed cellularity/ lymphocyte-depleted CHL, the IRR for UVR Q5 vs Q1 was 0.65 (95\% CI: $0.48-0.87, P$-trend $=0.056)$, whereas for those diagnosed at age $\geqslant 45$ years, the IRR for UVR Q5 vs Q1 was $0.74(95 \%$ CI: $0.55-1.00, P$-trend $=0.515$ ) (Supplementary Table 1). Among 7775 HL cases with information on birth state, $\sim 78 \%$ resided in the same tertile of UVR exposure at diagnosis as at birth.

\section{DISCUSSION}

In this large US population-based study of ambient UVR and HL subtypes, we found a significantly reduced risk of total HL, nodular sclerosis CHL, mixed cellularity/lymphocyte-depleted CHL, lymphocyte-rich CHL, and nodular lymphocyte predominant HL associated with increasing ambient UVR, but no relationship for CHL not otherwise specified. Our results strengthen the evidence for reduced risk of most HL subtypes in relation to high levels of ambient UVR.

Few studies have evaluated the relationship between UVR and specific subtypes of HL, and only one study has reported risk by all HL subtypes (van Leeuwen et al, 2013). In Australia, van Leeuwen et al (2013) conducted a cancer registry-based analysis that included $\sim 2400$ cases and assessed HL risk by specific subtype using three bands of latitude $\left(<29^{\circ} \mathrm{S}, 29^{\circ}-36^{\circ} \mathrm{S}\right.$ and $\left.\geqslant 37^{\circ} \mathrm{S}\right)$ as a surrogate for ambient UVR exposure. Our findings for an inverse association between UVR and nodular sclerosis CHL and mixed cellularity/lymphocyte-depleted CHL support the significant inverse trends reported in this study (van Leeuwen et al, 2013). However, van Leeuwen et al (2013) did not find an association between ambient UVR and the rare subtypes such as lymphocyterich CHL or nodular lymphocyte predominant HL. The small number of cases of lymphocyte-rich CHL $(n=151)$ and nodular lymphocyte predominant HL $(n=118)$ in that study limited the power to examine the relationship of UVR for these subtypes. Our null finding for CHL not otherwise specified is consistent with their null finding, but it is difficult to interpret the lack of a UVR relationship for this category because it is believed to mainly reflect difficulties in subclassification of small and suboptimal biopsies (Hjalgrim et al, 2007). The confidence bounds for NOS do overlap with most of the HL subtypes (Figure 2), so this null finding may also be due to chance.

Among studies assessing the relationship between UVR and total HL, our findings support some (Boscoe and Schymura, 2006; Monnereau et al, 2013), but not all, of the previous research demonstrating a reduced risk of HL with increasing exposure to UVR (Smedby et al, 2005; Petridou et al, 2007; Boffetta et al, 2008; Grandin et al, 2008; Chang et al, 2011; Wong et al, 2012). Our results agree with the only other United States-based study, which found a significantly reduced risk of total HL incidence and mortality in Southern states vs Northern states (Boscoe and Schymura, 2006). Case-control studies in both Europe (Smedby et al, 2005; Petridou et al, 2007; Boffetta et al, 2008; Grandin et al, 2008) and Asia (Wong et al, 2012) found no relationship between total HL and self-reported UVR exposure. However, the largest of these studies $(n=618)$ reported an inverse association between increasing sunlamp use and total HL risk $(P$-trend $=0.004$; Smedby et al, 2005), which agrees with our overall findings for total HL. Four pooled European case-control studies reported a significant inverse trend between increasing UVR exposure and total HL, with the strongest inverse relationship among EBVpositive tumours (odds ratio $=0.56 ; 95 \%$ CI: $0.35-0.91$; 
Table 1. Distribution of demographic characteristics for Hodgkin lymphoma cases by subtype, SEER 2001-2010

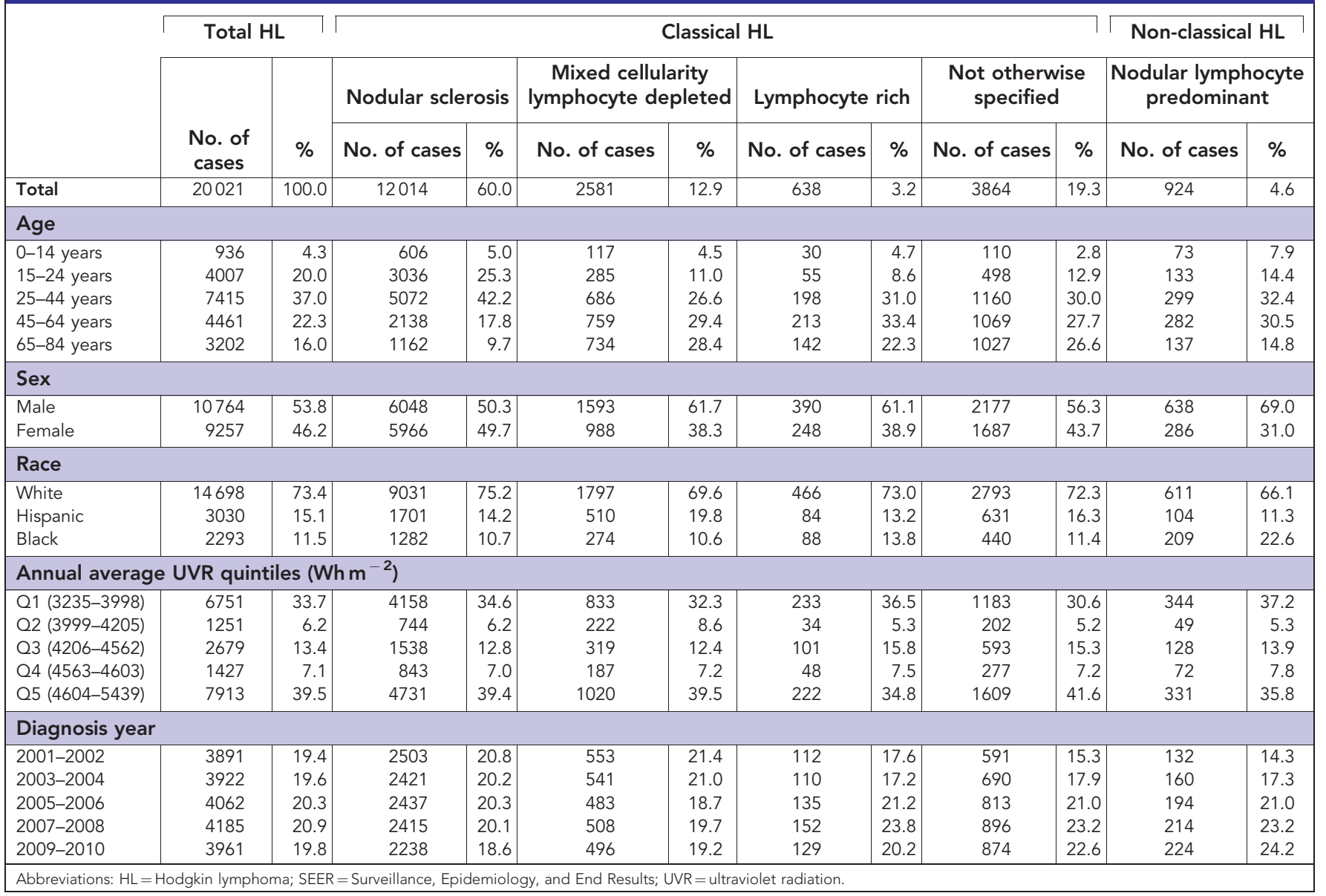

Table 2. Adjusted incidence rate ratios by quintile of ambient ultraviolet radiation for HL subtypes, SEER 2001-2010

\begin{tabular}{|c|c|c|c|c|c|c|c|c|c|c|c|c|c|c|c|c|c|c|}
\hline \multirow{4}{*}{$\begin{array}{l}\text { UVR quintile }^{c} \\
\text { Q1 }\end{array}$} & \multicolumn{3}{|c|}{ Total $\mathrm{HL}^{\mathrm{a}}$} & \multicolumn{12}{|c|}{ Classical $\mathrm{HL}^{\mathrm{b}}$} & \multicolumn{3}{|c|}{ Non-classical $\mathrm{HL}^{\mathrm{b}}$} \\
\hline & \multicolumn{3}{|c|}{$n=20021$} & \multicolumn{3}{|c|}{$\begin{array}{c}\text { Nodular } \\
\text { sclerosis } \\
n=12014\end{array}$} & \multicolumn{3}{|c|}{$\begin{array}{l}\text { Mixed cellularity } \\
\text { lymphocyte } \\
\text { depleted } \\
n=2581\end{array}$} & \multicolumn{3}{|c|}{$\begin{array}{c}\text { Lymphocyte } \\
\text { rich } \\
n=638\end{array}$} & \multicolumn{3}{|c|}{$\begin{array}{c}\text { Not } \\
\text { otherwise } \\
\text { specified } \\
n=3864\end{array}$} & \multicolumn{3}{|c|}{$\begin{array}{c}\text { Nodular } \\
\text { lymphocyte } \\
\text { predominant } \\
n=924\end{array}$} \\
\hline & \multirow[t]{2}{*}{$I_{R} R^{d}$} & \multicolumn{2}{|c|}{$95 \% \mathrm{Cl}$} & \multirow[t]{2}{*}{$I R^{d}$} & \multicolumn{2}{|c|}{$95 \% \mathrm{Cl}$} & \multirow[t]{2}{*}{ IRR $^{d}$} & \multicolumn{2}{|c|}{$95 \% \mathrm{Cl}$} & \multirow[t]{2}{*}{$\mathrm{IRR}^{\mathrm{d}}$} & \multicolumn{2}{|c|}{$95 \% \mathrm{Cl}$} & \multirow[t]{2}{*}{ IRR $^{d}$} & \multicolumn{2}{|c|}{$95 \% \mathrm{Cl}$} & \multirow[t]{2}{*}{ IRR $^{d}$} & \multicolumn{2}{|c|}{$95 \% \mathrm{Cl}$} \\
\hline & & & Ref & & & Ref & & & Ref & & & Ref & & & Ref & & & Ref \\
\hline Q3 & 0.89 & 0.82 & 0.97 & 0.86 & 0.76 & 0.97 & 0.77 & 0.60 & 1.00 & 0.93 & 0.72 & 1.19 & 1.16 & 0.94 & 1.44 & 0.75 & 0.55 & 1.01 \\
\hline Q4 & 0.84 & 0.76 & 0.92 & 0.83 & 0.72 & 0.96 & 0.88 & 0.66 & 1.17 & 0.76 & 0.55 & 1.06 & 0.93 & 0.74 & 1.19 & 0.72 & 0.51 & 1.02 \\
\hline Q5 & 0.88 & 0.81 & 0.95 & 0.84 & 0.75 & 0.96 & 0.66 & 0.51 & 0.86 & 0.71 & 0.57 & 0.88 & 1.19 & 0.96 & 1.47 & 0.74 & 0.56 & 0.97 \\
\hline$P$ for trend ${ }^{\mathbf{e}}$ & & & $<0.001$ & & & $<0.001$ & & & 0.106 & & & 0.005 & & & 0.503 & & & $<0.001$ \\
\hline \multicolumn{19}{|c|}{ 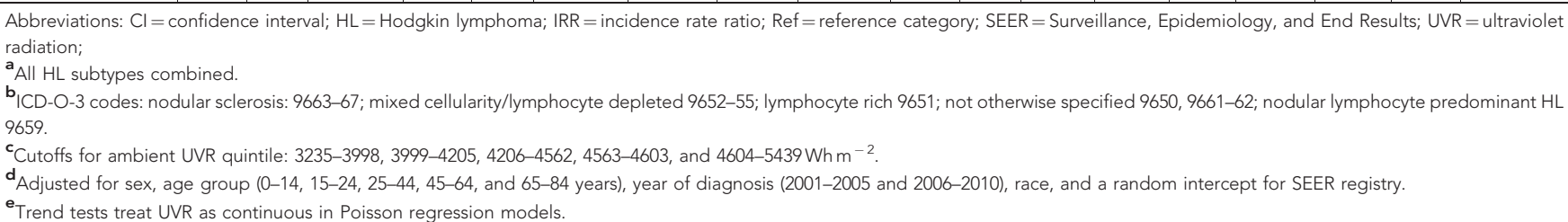 } \\
\hline
\end{tabular}

Monnereau et al, 2013). Our finding that UVR is inversely related to mixed cellularity/lymphocyte-depleted CHL agrees with these results because up to $80 \%$ of mixed cellularity/lymphocyte-depleted CHL cases are believed to be EBV positive(Glaser et al, 1997).
Although we did not have the EBV status of our cases, we did find the strongest inverse association for the highest quintile of UVR for mixed cellularity/lymphocyte-depleted CHL $(\mathrm{IRR}=0.66$; 95\% CI: $0.51,0.86)$. 


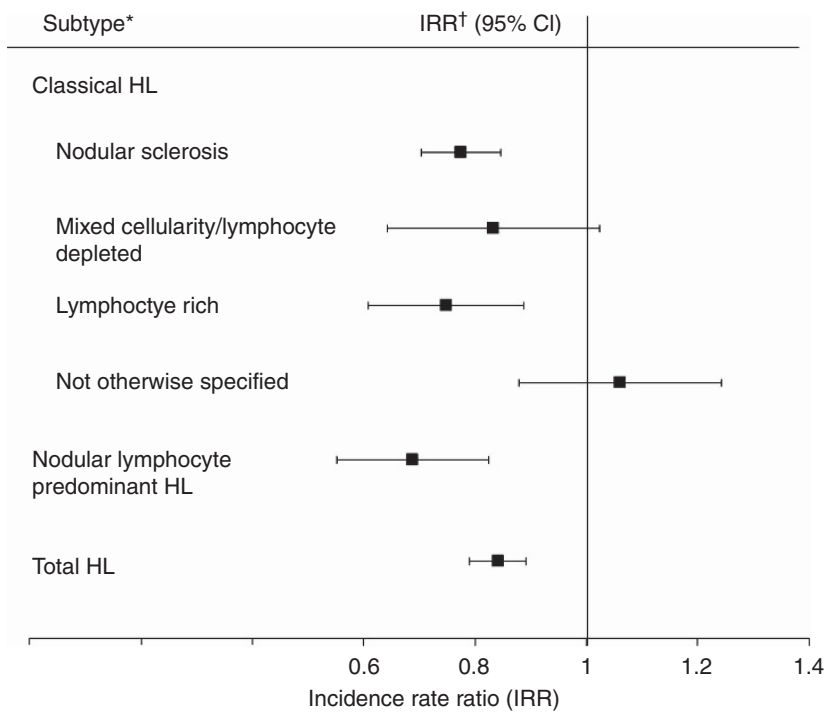

Figure 2. Incidence rate ratios (IRRs) and $95 \%$ confidence intervals (Cl) of Hodgkin lymphoma subtypes for $1000 \mathrm{Wh} \mathrm{m}^{-2}$ of UVR in the Surveillance, Epidemiology, and End Results Program between 2001 and 2010. *ICD-0-3 codes: nodular sclerosis 9663-67; mixed cellularity/ lymphocyte depleted 9652-55; lymphocyte rich 9651; classical not otherwise specified 9650, 9661-62; nodular lymphocyte predominant $\mathrm{HL}$ 9659. 'Model contains sex, age group (0-14, 15-24, 25-44, 45-64, $65-84$ years), continuous UVR (1000 $\left.\mathrm{Wh} \mathrm{m}^{-2}\right)$, race, year of diagnosis (2001-2005, 2006-2010), and SEER registry. Note: $1000 \mathrm{Wh} \mathrm{m}^{-2}$

corresponds to approximately a 600-mile north-south distance on the east coast of the United States. $\mathrm{Cl}=$ confidence interval; $\mathrm{HL}=$ Hodgkin lymphoma; IRR = incidence rate ratio; UVR= ultra-violet radiation.

Exposure to UVR is associated with a number of systemic immunologic changes (Clydesdale et al, 2001; Hart et al, 2011; Ullrich and Byrne, 2012). Ultraviolet radiation causes the induction of regulatory $\mathrm{T}$ cells (Schwarz, 2008), which inhibit chronic inflammation and may potentially reduce cancer risk (Erdman and Poutahidis, 2010). Exposure to ambient UVR also contributes to the production of endogenous vitamin $\mathrm{D}$, which has been shown to be protective for other lymphoid cancers (Lim et al, 2009; Luczynska et al, 2013). However, 25-hydroxyvitamin D is not known to be associated with risk of HL. It has also been suggested that the induction of nitric oxide by UVR, independently of vitamin $\mathrm{D}$, may be responsible for a number of circulatory system changes (Liu et al, 2014). Numerous studies have suggested an inverse relationship between UVR and some B-cell non-HL subtypes (Smedby et al, 2005; Boffetta et al, 2008; Chang et al, 2011; van Leeuwen et al, 2013; Cahoon et al, 2014). Shared clinicopathological and molecular features between some HL and B-cell non-HL subtypes suggest that UVR may have a similar role in these two major types of lymphoma (Menon et al, 2012; Hartmann et al, 2013).

An important strength of this study is a sample size large enough to examine all HL subtypes and evaluate potential modifying effects by sex, age, and race/ethnicity. This study encompasses a broad range of ambient UVR for a geographically dispersed population, and uses county-level ground-based ambient UVR estimates recently made available for epidemiological research. Despite these strengths, our study also has several limitations. We lack information on individual-level risk factors such as EBV status, autoimmune disorders (Fallah et al, 2014), alcohol consumption (Tramacere et al, 2012), body mass index (Murphy et al, 2013), and individual measures of sun exposure (e.g., sun protective behaviours, time outdoors, and location of residence throughout the lifetime). We found significant inverse associations of total HL and mixed cellularity/lymphocyte-depleted CHL with UVR for individuals $<45$ years of age but not those 45 years and older. Ambient UVR may be assigned more accurately to people who are younger because they have had less opportunity to move before cancer diagnosis. As UVR was linked to the location of residence only at the time of diagnosis, greater misclassification may explain the null findings in older people. However, an analysis among HL cases in SEER with information on birth state suggested that the large majority of cases lived in a similar UVR at diagnosis and birth.

In summary, this US population-based study of ambient UVR and HL showed a significant reduction in risk for all HL subtypes except CHL not otherwise specified. Our results support and expand the limited evidence for an association between UVR and HL, especially the rare subtypes of lymphocyte-rich CHL and nodular lymphocyte predominant HL. Future research should focus on more detailed personal UVR exposure assessment and control for individual-level HL risk factors such as EBV status.

\section{ACKNOWLEDGEMENTS}

We thank Kimia Zarabian for computing support. This research was supported by the Intramural Research Program, Division of Cancer Epidemiology and Genetics, National Cancer Institute, National Institutes of Health, US Department of Health and Human Services.

\section{CONFLICT OF INTEREST}

The authors declare no conflict of interest.

\section{REFERENCES}

Boffetta P, van der Hel O, Kricker A, Nieters A, de Sanjose S, Maynadie M, Cocco PL, Staines A, Becker N, Font R, Mannetje A, Goumas C, Brennan P (2008) Exposure to ultraviolet radiation and risk of malignant lymphoma and multiple myeloma-a multicentre European case-control study. Int J Epidemiol 37(5): 1080-1094.

Boscoe FP, Schymura MJ (2006) Solar ultraviolet-B exposure and cancer incidence and mortality in the United States, 1993-2002. BMC Cancer 6: 264.

Cahoon EK, Pfeiffer RM, Wheeler DC, Arhancet J, Lin S-W, Alexander BH, Linet MS, Freedman DM (2014) Relationship between ambient ultraviolet radiation and non-Hodgkin lymphoma subtypes: A U.S. population-based study of racial and ethnic groups. Int J Cancer 136(5): E432-E441.

Carbone A, Gloghini A, Serraino D, Spina M (2009) HIV-associated Hodgkin lymphoma. Curr Opin HIV AIDS 4(1): 3-10.

Cartwright RA, Watkins G (2004) Epidemiology of Hodgkin's disease: a review. Hematol Oncol 22(1): 11-26.

Chang ET, Canchola AJ, Cockburn M, Lu Y, Wang SS, Bernstein L, Clarke CA, Horn-Ross PL (2011) Adulthood residential ultraviolet radiation, sun sensitivity, dietary vitamin $\mathrm{D}$, and risk of lymphoid malignancies in the California Teachers Study. Blood 118(6): 1591-1599.

Clydesdale GJ, Dandie GW, Muller HK (2001) Ultraviolet light induced injury: immunological and inflammatory effects. Immunol Cell Biol 79(6): 547-568.

Cochran WG (1954) The combination of estimates from different experiments. Biometrics 10: 101-129.

Erdman SE, Poutahidis T (2010) Cancer inflammation and regulatory $\mathrm{T}$ cells. Int J Cancer 127(4): 768-779.

Fallah M, Liu X, Ji J, Forsti A, Sundquist K, Hemminki K (2014) Hodgkin lymphoma after autoimmune diseases by age at diagnosis and histological subtype. Ann Oncol 25(7): 1397-1404.

Fritz AG (2000) International Classification of Diseases for Oncology: ICD-O. World Health Organization. 
Glaser SL, Lin RJ, Stewart SL, Ambinder RF, Jarrett RF, Brousset P, Pallesen G, Gulley ML, Khan G, O'Grady J, Hummel M, Preciado MV, Knecht H, Chan JK, Claviez A (1997) Epstein-Barr virus-associated Hodgkin's disease: epidemiologic characteristics in international data. Int J Cancer 70(4): 375-382.

Grandin L, Orsi L, Troussard X, Monnereau A, Berthou C, Fenaux P, Marit G, Soubeyran P, Huguet F, Milpied N, Leporrier M, Hemon D, Clavel J (2008) UV radiation exposure, skin type and lymphoid malignancies: results of a French case-control study. Cancer Causes Control 19(3): 305-315.

Hart PH, Gorman S, Finlay-Jones JJ (2011) Modulation of the immune system by UV radiation: more than just the effects of vitamin D? Nat Rev Immunol 11(9): 584-596.

Hartmann S, Doring C, Jakobus C, Rengstl B, Newrzela S, Tousseyn T, Sagaert X, Ponzoni M, Facchetti F, de Wolf-Peeters C, Steidl C, Gascoyne R, Kuppers R, Hansmann ML (2013) Nodular lymphocyte predominant hodgkin lymphoma and $\mathrm{T}$ cell/histiocyte rich large $\mathrm{B}$ cell lymphoma-endpoints of a spectrum of one disease? PLoS One 8(11): e78812.

Hjalgrim H, Smedby KE, Rostgaard K, Molin D, Hamilton-Dutoit S, Chang ET, Ralfkiaer E, Sundstrom C, Adami HO, Glimelius B, Melbye M (2007) Infectious mononucleosis, childhood social environment, and risk of Hodgkin lymphoma. Cancer Res 67(5): 2382-2388.

Howlader N, Noone A, Krapcho M, Garshell J, Miller D, Alterkeruse S, Kosary C, Yu M, Ruhl J, Tatalovich Z, Mariotto A, Lewis D, Chen H, Feuer E, Cronin K (eds) (1975-2011) SEER Cancer Statistics Review. National Cancer Institute: Bethesda, MD, USA.

Jaffe ES, Harris NL, Diebold J, Muller-Hermelink H-K (1999) World Health Organization classification of neoplastic diseases of the hematopoietic and lymphoid tissues. A progress report. Am J Clin Pathol 111(1 Suppl 1): S8-S12.

Jarrett AF, Armstrong AA, Alexander E (1996) Epidemiology of EBV and Hodgkin's lymphoma. Ann Oncol 4: 5-10.

Jarrett RF (2002) Viruses and Hodgkin's lymphoma. Ann Oncol 1: 23-29.

Lean JL, Rottman GJ, Kyle HL, Woods TN, Hickey JR, Puga LC (1997) Detection and parameterization of variations in solar mid- and nearultraviolet radiation (200-400 nm). J Geophys Res Atmospheres 102(D25): 29939-29956

Lim U, Freedman DM, Hollis BW, Horst RL, Purdue MP, Chatterjee N, Weinstein SJ, Morton LM, Schatzkin A, Virtamo J, Linet MS, Hartge P, Albanes D (2009) A prospective investigation of serum 25-hydroxyvitamin $\mathrm{D}$ and risk of lymphoid cancers. Int J Cancer 124(4): 979-986.

Liu D, Fernandez BO, Hamilton A, Lang NN, Gallagher JM, Newby DE, Feelisch M, Weller RB (2014) UVA irradiation of human skin vasodilates arterial vasculature and lowers blood pressure independently of nitric oxide synthase. J Invest Dermatol 134(7): 1839-1846.

Luczynska A, Kaaks R, Rohrmann S, Becker S, Linseisen J, Buijsse B, Overvad K, Trichopoulou A, Valanou E, Barmpitsioti A, Masala G, Agnoli C, Tumino R, Panico S, Bueno-de-Mesquita HB, van Duijnhoven FJ, Peeters PH, Vermeulen R, Weiderpass E, Brustad M, Skeie G, Gonzalez CA, Jakszyn P, Quiros JR, Sanchez MJ, Huerta JM, Ardanaz E, Melin B, Johansson AS, Almquist M, Malm J, Khaw KT, Wareham N, Travis RC, Fedirko V, Romieu I, Jenab M, Gallo V, Riboli E, Vineis P, Nieters A (2013) Plasma 25-hydroxyvitamin D concentration and lymphoma risk: results of the European Prospective Investigation into Cancer and Nutrition. Am J Clin Nutr 98(3): 827-838.

Mani H, Jaffe ES (2009) Hodgkin lymphoma: an update on its biology with new insights into classification. Clin Lymphoma Myeloma 9(3): 206-216.

Menon MP, Pittaluga S, Jaffe ES (2012) The histological and biological spectrum of diffuse large B-cell lymphoma in the World Health Organization classification. Cancer J 18(5): 411-420.

Monnereau A, Glaser SL, Schupp CW, Ekstrom Smedby K, de Sanjose S, Kane E, Melbye M, Foretova L, Maynadie M, Staines A, Becker N, Nieters A, Brennan P, Boffetta P, Cocco P, Glimelius I, Clavel J, Hjalgrim H, Chang ET (2013) Exposure to UV radiation and risk of Hodgkin lymphoma: a pooled analysis. Blood 122(20): 3492-3499.

Morton LM, Turner JJ, Cerhan JR, Linet MS, Treseler PA, Clarke CA, Jack A, Cozen W, Maynadié M, Spinelli JJ (2007) Proposed classification of lymphoid neoplasms for epidemiologic research from the Pathology Working Group of the International Lymphoma Epidemiology Consortium (InterLymph). Blood 110(2): 695-708.

Murphy F, Kroll ME, Pirie K, Reeves G, Green J, Beral V (2013) Body size in relation to incidence of subtypes of haematological malignancy in the prospective Million Women Study. Br J Cancer 108(11): 2390-2398.

Newman P, Herman J, Bevilacqua R, Stolarski R, Keating T (2008) Trends in emissions of ozone-depleting substances, ozone layer recovery, and implications for ultraviolet radiation exposure. In US Climate Change Science Program and the Subcommittee on Global Change Research. UNT Digital Library: Washington, DC, USA. Available from http://digital.library.unt.edu/ark:/67531/metadc12023/ (accessed 4 February 2016).

Petridou ET, Dikalioti SK, Skalkidou A, Andrie E, Dessypris N, Trichopoulos D (2007) Sun exposure, birth weight, and childhood lymphomas: a case control study in Greece. Cancer Causes Control 18(9): 1031-1037.

Schwarz T (2008) 25 years of UV-induced immunosuppression mediated by $\mathrm{T}$ cells-from disregarded $\mathrm{T}$ suppressor cells to highly respected regulatory T cells. Photochem Photobiol 84(1): 10-18.

Shiels MS, Koritzinsky EH, Clarke CA, Suneja G, Morton LM, Engels EA (2014) Prevalence of HIV Infection among U.S. Hodgkin lymphoma cases. Cancer Epidemiol Biomarkers Prev 23(2): 274-281.

Smedby KE, Hjalgrim H, Melbye M, Torrang A, Rostgaard K, Munksgaard L, Adami J, Hansen M, Porwit-MacDonald A, Jensen BA, Roos G, Pedersen BB, Sundstrom C, Glimelius B, Adami HO (2005) Ultraviolet radiation exposure and risk of malignant lymphomas. J Natl Cancer Inst 97(3): 199-209.

StataCorp (2015) Stata Statistical Software: Release. StataCorp LP: College Station, TX, USA.

Surveillance, Epidemiology, and End Results (SEER) Program (2013) SEER ${ }^{\star}$ Stat Database: Incidence-SEER 18 Regs Custom Data (includes additional CS SSF data for 2010 cases), Nov 2012 Sub (2000-2010) $<$ Katrina/Rita Population Adjustment $>$-Linked To County AttributesTotal U.S., 1969-2011 Counties. National Cancer Institute, DCCPS, Surveillance Research Program, Surveillance Systems Branch, www.seer.cancer.gov (released May 2013, based on the November 2012 submission).

Tatalovich Z, Wilson JP, Cockburn M (2006) A comparison of thiessen polygon, kriging, and spline models of potential UV exposure. Cartogr Geogr Inf Sci 33(3): 217-231.

Tramacere I, Pelucchi C, Bonifazi M, Bagnardi V, Rota M, Bellocco R, Scotti L, Islami F, Corrao G, Boffetta P, La Vecchia C, Negri E (2012) A metaanalysis on alcohol drinking and the risk of Hodgkin lymphoma. Eur J Cancer Prevention 21(3): 268-273.

Turner JJ, Morton LM, Linet MS, Clarke CA, Kadin ME, Vajdic CM, Monnereau A, Maynadié M, BC-H Chiu, Marcos-Gragera R (2010) InterLymph hierarchical classification of lymphoid neoplasms for epidemiologic research based on the WHO classification (2008): update and future directions. Blood 116(20): e90-e98.

Ullrich SE, Byrne SN (2012) The immunologic revolution: photoimmunology. J Invest Dermatol 132(3 Pt 2): 896-905.

van Leeuwen MT, Turner JJ, Falster MO, Meagher NS, Joske DJ, Grulich AE, Giles GG, Vajdic CM (2013) Latitude gradients for lymphoid neoplasm subtypes in Australia support an association with ultraviolet radiation exposure. Int J Cancer 133(4): 944-951.

Wong KY, Tai BC, Chia SE, Kuperan P, Lee KM, Lim ST, Loong S, Mow B, Ng SB, Tan L, Tan SY, Tan SH, Tao M, Wong A, Wong GC, Seow A (2012) Sun exposure and risk of lymphoid neoplasms in Singapore. Cancer Causes Control 23(7): 1055-1064.

Yung L, Linch D (2003) Hodgkin's lymphoma. Lancet 361(9361): 943-951.

This work is published under the standard license to publish agreement. After 12 months the work will become freely available and the license terms will switch to a Creative Commons AttributionNonCommercial-Share Alike 4.0 Unported License. 